\title{
Mission
}

The objective of Management Control journal is to publish high quality theoretical and empirical studies in line with the international standards. The journal is open to different research methodologies, either quantitative or qualitative, and welcomes an inductivedeductive research method, in line with the traditional Italian accounting and management studies. The journal aims to investigate the topic of control systems, in their evolution as a guide-control systems in the different organizational areas and at various levels of decision making.

The journal welcomes papers in the following thematic areas:

1. forecasting, business planning and management control systems (Planning \& Budgeting area);

2. cost measurement and management, and performance systems (Cost-Performance area);

3. information and reporting systems, with analyses dedicated to the design and management of information systems, including their organizational and technological components (Information Systems area);

4. management audit systems, with analyses on the verification of the effectiveness of both information and management operations with a critical analysis of control systems (Management Audit area).

The papers submitted will be subject to a preliminary screening for consistency with the editorial line and objectives of the journal. The papers accepted for review will subject to a double blind refereeing (peer review) process, according to international standards.

\section{Editorial Standards}

Articles submitted for publication must comply with the following standards.

1. Papers must be sent via email to rivistaMC@ec.unipi.it using the "articolo_MC.doc" model;

2. The names of the authors should be entered in a separate file, indicating both home institution and e-mail addresses in footnote, according to the "riferimenti_autore_MC.doc";

3. An abstract in English of about 1200 characters should be provided. The title of the article, always in English, should be added in the first line of the abstract. From two to six keywords must be indicated at the end of the abstract (these keywords are used for indexing the article in the international databases). The body of the abstract and keywords must be in Times New Roman, size 10, single-spaced.

Management Control (ISSN 2239-0391, ISSNe 2239-4397), 2017, 2

DOI: 10.3280/MACO2017-002008 
4. Single essays including notes, references, charts and tables should not exceed 25 pages of 2800 characters each (for a total of $\mathbf{7 0 , 0 0 0}$ characters including spaces).

5. Page Setup. The layout of the page should be as follows:

- Top margin: $5.5 \mathrm{~cm}$, bottom: $6.2 \mathrm{~cm}$, left: $4.6 \mathrm{~cm}$, right: $4.6 \mathrm{~cm}$;

- header: $4.3 \mathrm{~cm}$;

- footer: $5.3 \mathrm{~cm}$;

- binding: 0;

- spacing: single;

- choose "Facing Pages";

- in the "Layout" tab click "different odd and even" and "different first page".

- Spell out the entire document.

\section{Text character}

Body: Times New Roman, size 11, justified, single spacing, indentation of first line $0.5 \mathrm{~cm}$ activating the control of isolated lines.

Title of article: Times New Roman, size 16, bold, centered.

Titles of sections and subsections: Times New Roman, size 11, bold, 2 white line-spacing above and 1 below, numbered consecutively.

Notes (footer): Times New Roman, size 9, single-spaced, first line indent $0.5 \mathrm{~cm}$, numbered consecutively from footnote $\mathrm{n} .1$.

References: Times New Roman, size 9, single spacing, hanging indent $0.5 \mathrm{~cm}$.

Caption: Times New Roman, 9, on the right-hand pages (odd) must bear the title of the article or section title, right-aligned, possibly shortening the title for the header is on a single line.

Footer: insert page numbers, Times New Roman, size 11, centered, with no return, no frame, at $0.8 \mathrm{~cm}$ from the foot of the last row.

Bullets and Numbering: left indent to $0 \mathrm{~cm}, 0.5 \mathrm{~cm}$ hanging indent.

7. References included in the text should be enclosed between parentheses and the author's last name should be followed by a comma, year of publication and eventually the page (Giannessi, 1960, p. 56). If the authors are two, they must be both written and connected by "and". In the case of three or more authors, use the first name followed by et al. in italics. (Anthony et al., 1979).

8. References at the end of the text. The title "References" should be entered with the same format as section headings.

All authors quoted in the text will be given at the end of the essay in alphabetical and chronological order (for more works by the same author). As for works by the same author published in the same year, we will use the directions a, b, c. (Coda, 1981a). In the case of multiple authors, the surnames of all of them must be given.

In the case of collective volumes, it must be indicated the name of the editor accompanied by the expression (a cura di) for editions in Italian (ed. or eds) for those one in English. The articles in English are distinguished by initial lowercase letters, journals and books will be using initial capital letters.

The references should be prepared in accordance with the rules implied by the following examples: 


\section{References}

\section{Books:}

Brunetti G. (1992), Il controllo di gestione in condizioni ambientali perturbate, Milano, FrancoAngeli.

Kaplan R.S., Atkinson S. (2002), Advanced Management Accounting, Upper Saddle River, Prentice Hall (trad. it.: Bianchi C., Bubbio A., a cura di, Advanced Management Accounting. Gli strumenti del controllo di gestione, Torino, Isedi, 2002).

\section{Edited books:}

Amigoni F., Miolo Vitali P., a cura di (2003), Misure multiple di performance, Milano, Egea.

Rust R.T., Oliver R., eds (1994), Service Quality: New Directions in Theory and Practice, Thousand Oaks, Sage Publications.

\section{Book sections:}

Riccaboni A. (2009), Il controllo di gestione. Obiettivi, attori e strumenti, in Marasca S., Marchi L., Riccaboni A., a cura di, Controllo di gestione: metodologie e strumenti, Arezzo, Knowità Editore.

Austin R., Hoffer Jittel J. (2002), When it should not work but does: anomalies of high performance, in Neely A. editor, Business performance measurement, Cambridge University Press.

\section{Articles in journal:}

Malmi T., Brown D.A. (2008), Management control systems as a package - opportunities, challenges and research directions, Management Accounting Research, 19, 4, pp. $287-$ 300. Doi: 10.1016/j.mar.2008.09.003.

Anderson S. H., Hesford J.W., Young S.M. (2002), Factors influencing the performance of activity based costing teams: a field study of $\mathrm{ABC}$ model development time in the automobile industry, Accounting, Organizations and Society, 27, pp. 195-211. Doi: 10.1016/S0361-3682(01)00057-5.

9. Figures, tables and charts must be entered in the text in a format so as to allow any subsequent interventions. There cannot be tables and / or figures in the appendix or as attachments.

The captions should be set in Times New Roman, size 10, italics.

Any source is inserted below the table or figure, must be set as the caption, but the character of the quotation must be round (see example).

The table will be set in Times New Roman, size 10, header at the top: italic, with a black thread above and below (see example).

\section{TABLE EXAMPLE:}

Tab. 3 - Cambiamenti percepiti nel ruolo del budget

\begin{tabular}{lccc}
\hline & Incremento & Rimane stabile & Decremento \\
\hline Settore manifatturiero & 8,1 & 35,7 & 46,2 \\
Servizi finanziari & 14,7 & 50,8 & 34,5 \\
Servizi pubblici & 27,2 & 41,1 & 31,7 \\
Valore medio & 16,7 & 42,5 & 37,5 \\
\hline
\end{tabular}

Source: D’Onza, 2011, p. 170. 
10. Text and quotations setting. There are three character types: normal, bold and italics. Italics, to be used sparingly, should highlight words or short sentences. To give greater prominence to words or phrases and for non-literal quotations, it is preferable to use "curly quotes", while exact quotations are in «angle quotes». For quoted parts in a sentence already quoted, apostrophes should be used. As for illustration of results and data, the use of tables must be privileged with respect to the illustrations. The latter should only be used in exceptional cases, where it is impossible to use the tables for technical reasons.

It is also to be highlighted that:

- Texts in definitive form should be sent by e-mail to the editor of the journal in WORD format (Not valid PDF format);

- The journal accepts only original articles;

- The editorials "by invitation " are published upon the invitation of the Editorial Board of the journal;

- Articles submitted for publication are subject to the evaluation of two anonymous referees for acceptance; in case of discrepancy between the two evaluations a third referee is called for;

- Authors should keep in mind the debate previously developed in the articles published in the journal;

- Papers must be accompanied by a letter of release in which the author grants to the Direction of the journal the exclusive exploitation rights on the article. 